\title{
Configurações
}

Revista de sociologia

Debater o desenvolvimento: questões, dilemas e alternativas

\section{In memoriam - Theotônio dos Santos: Legado e atualidade no campo das ciências sociais latino americanas (a propósito das onze teses sobre a herança neoliberal)}

Ivonaldo Leite

\section{OpenEdition \\ Journals}

Edição electrónica

URL: http://journals.openedition.org/configuracoes/9093

DOI: 10.4000/configuracoes.9093

ISSN: 2182-7419

\section{Editora}

Centro de Investigação em Ciências Sociais

Edição impressa

Paginação: 170-182

ISSN: 1646-5075

\section{Refêrencia eletrónica}

Ivonaldo Leite, «In memoriam - Theotônio dos Santos: Legado e atualidade no campo das ciências sociais latino americanas (a propósito das onze teses sobre a herança neoliberal) », Configurações [Online], 25 | 2020, posto online no dia 23 junho 2020, consultado o 25 junho 2020. URL : http:// journals.openedition.org/configuracoes/9093; DOI : https://doi.org/10.4000/configuracoes.9093 
Leite, Ivonaldo - Theotônio dos Santos: Legado e atualidade no campo das ciências sociais latino americanas (a propósito das onze teses sobre a herança neoliberal). Configurações, vol. 25, 2020, pp. 170-182.

\section{Theotônio dos Santos: Legado e atualidade no campo das ciên- cias sociais latino americanas (a propósito das onze teses sobre a herança neoliberal)}

IVONALDO LEITE*

Departamento de Educação da Universidade Federal da Paraíba

A morte, como disse Hegel, se quisermos chamar assim essa irrealidade, é a coisa mais espantosa, e guardar o que está morto é o que exige uma maior firmeza. Ela é, por um lado, o resultado final do processo de um indivíduo singular, que vive e age numa sociedade universal, e, por outro lado, ela é a negatividade natural do indivíduo que ocorre no tempo, mas que cancela o tempo absoluto do indivíduo que morre'. Esta coisa espantosa cancela a existência consciente do indivíduo, indivíduo que só pode existir no espaço e no tempo, na História. A morte faz o indivíduo sair da universalidade quieta, da negatividade abstrata. A esta universalidade quieta, o morto é remetido como originalidade natural, como ente que, assim sendo, deixa de ser uma diferença, deixa de ser uma alteridade e um outro. Ele volta ao mesmo, ao nada. Pelo que, na morte natural, como cancelamento da alteridade existente, não se pode encontrar nenhum consolo e nem reconciliação.

O indivíduo, ao morrer, regressa à indiferencialidade da natureza, cancelando-se a sua extensividade ativa e consciente. Cindindo-se o ser individual do agir no morto, ele torna-se uma singularidade vazia e passiva. Passa a ser lembrança de um nome carente de realidade. Este nome é somente nome para os outros que o lembram. Ele deixou de ser nome para si mesmo, ele deixou de ser autorreferência. Por isto, a maioria dos mortos permanece como uma lembrança quieta na sombra 
das famílias, e então assim pode-se dizer que esta visão sobre a morte constitui $o$ lado morto do morto ou a morte do indivíduo propriamente natural.

Se o indivíduo for pensado somente como indivíduo até ao fim, e é necessário - por um momento - que assim ele o seja, o indivíduo pensado será um indivíduo natural. Então, dessa maneira, o fim é trágico. Não há saída. Para a universal pergunta Para onde vamos?, só existe uma resposta: "Para lado nenhum."

Mas, e que pensamentos e sentimentos experimentamos em relação ao desaparecimento de um ente querido? Aqui parece que é possível estabelecer uma analogia em relação àquilo que Hegel expressou no que concerne à contemplação das ruínas históricas. A morte e as ruínas históricas evocam necessariamente uma reflexão sobre a degradação temporal, sobre o irrecorrível desaparecimento dos indivíduos e das coisas. Os sentimentos que experimentamos perante este tribunal do tempo nos provocam uma deprimente tristeza. Constatamos que uma vitalidade consciente, um indivíduo estimado e querido, teve de morrer, e nos atormentamos no desconsolo das lembranças.

Assim é a morte. Ela nos proporciona uma pergunta sem resposta: "Por quê?". Por não termos resposta, emerge uma dor profunda e, diante desta instância incontrolável, a melancolia que nos invade ora nos oprime na sensação do desaparecimento total e ora nos indaga sobre o significado e a validade das vidas individuais. Se a sensação vazia do desaparecimento que sentimos, diante do túmulo, nos provoca o luto e nos aprisiona à passividade, é na indagação sobre o significado e a validade das vidas individuais onde podemos encontrar o caminho que nos conduz a superar a imaginação nostálgica, para nos devolver ao mundo ativo da História.

Perante o morto não há consolo, pois ele pertence ao domínio do desaparecimento e da finitude. Somente com o nosso regresso ao mundo ativo da História dos seres humanos vivos, podemos nos reconciliar com a universalidade da vida. Quer dizer, é na reconciliação com a vida, que nos nega consolo, que temos o lugar onde poderemos encontrar a valorização do desaparecido. Contudo, não como desaparecido, mas na expressão de sua universalidade vivida, no produto da sua atividade, que se apresenta como legado, e na significação exemplificativa da sua vida. Isto é, o que sobrevive é a produção consciente e socialmente significativa do indivíduo. De onde decorre que quanto mais universal for esta produção, mais ele sobrevive.

Começo por colocar em realce estas notas de cariz hegeliano neste ensaio sobre Theotônio dos Santos exatamente por elas, em determinada medida, aportarem bases para uma dupla perspectiva a seu respeito: a superação do sentimento de impotência nostálgica em decorrência do seu falecimento e a compreensão da sua sobrevivência através da obra universal que ele produziu. Assim digo tendo a presença de um acentuado sentimento de natureza pessoal.

Muito cedo tomei contacto com os trabalhos de Theotônio dos Santos. Desde logo, chamou-me bastante a atenção, por exemplo, o pequeno (mas significativo) 
livro Concepto de clases sociales ${ }^{2}$. Mais adiante, Dependencia y cambio social ${ }^{3}$, também assim mesmo, o acesso se deu a uma versão em espanhol, o que me intrigava: o facto de um brasileiro, bastante conhecido fora do Brasil, não se encontrar traduzido em seu próprio país. Posteriormente, ao ler sobre algumas polêmicas envolvendo Ruy Mauro Marini e Fernando Henrique Cardoso a propósito da Teoria da Dependência, dei-me conta de que, para além das implicações decorrentes de Dos Santos ter construído sua obra no exílio imposto pela ditadura brasileira, existiam outras razões para o "silêncio" em torno dos seus trabalhos no Brasil, assim como em relação aos de Marini.

A culminância dessa interação com as abordagens de Theotônio deu-se de forma direta ao frequentar um curso levado a cabo por ele nos anos 1990. Nessa altura, já apresentava o que viria a ser o seu balanço da Teoria da Dependência, levando-a ao encontro da Escola do Sistema Mundo. De resto, ficaram-me gravadas, até hoje, as suas palavras na intervenção final. Algo mais ou menos nos seguintes termos: "conhecer a realidade requer um percurso metodológico totalizante, superando fronteiras disciplinares, para chegar a uma verdade científica que não é apática, mas ativa."

Foram estas suas palavras que me vieram à mente ao tomar conhecimento do seu falecimento. Não sei ao certo, mas talvez também tenham sido tais palavras, configuradas de outra forma, que me chamaram a atenção logo que, ainda muito jovem, dei uma primeira vista de olhos em seus textos. Conforme as atiladas páginas que Sérgio Buarque de Holanda escreveu em Raízes do Brasil ${ }^{4}$, chega certa altura da vida que vai ficando possível dar balanço no passado sem cair na autocomplacência, pois o nosso testemunho se torna registro da experiência de muitos, de todos que, pertencendo ao que se denomina uma geração, se julgam, a princípio, diferentes uns dos outros e vão, aos poucos, ficando tão iguais que acabam desaparecendo como indivíduos, para se dissolverem nas características gerais da sua época. Então, narrar o passado não é falar de si; é falar dos que participaram de uma certa ordem de interesses e de visão do mundo, no momento particular do tempo que se deseja evocar.

Tenho presente essa asserção, e penso até mesmo que ela é imperativa quando se trata do legado de Theotônio dos Santos, na medida em que ele deu expressão mundial ao estilo de análise de uma geração de cientistas sociais latino-americanos. 


\section{A dimensão da ciência social latino-americana e Theotônio dos Santos}

A partir da segunda metade do século XX, a América Latina propiciou ao mundo um modo de análise social marcadamente original: uma perspectiva metodológica inter/transdisciplinar, sem fazer concessões à compartimentalização do conhecimento, com foco na integralidade dos fenômenos, captando-os em conjunturas sócio-históricas concretas, buscando construir quadros de inteligibilidade para orientar ações de transformação social, etc. Foi nesse quadro que se moveram os teóricos da Escola da Dependência, ou Teoria da Dependência, como é mais conhecida.

Theotônio dos Santos insere-se nesse conjunto de cientistas sociais latino-americanos que lograram construir uma obra cosmopolita e com fecundidade analítica. Natural do estado de Minas Gerais, no sudeste do Brasil, era sociólogo e economista. Quando do golpe civil-miliar de 1964, encontrava-se como professor da Universidade de Brasília (UnB), sendo demitido, o que o levou ao exílio no Chile, vinculando-se ao Centro de Estudos Socioeconômicos da Faculdade de Economia da Universidade do Chile, onde coordenou diversos estudos e debates que levaram ao desenvolvimento da Teoria da Dependência, dos quais participaram, entre outros, Ruy Mauro Marini, Vania Bambirra e Fernando Henrique Cardoso. Com o golpe militar no Chile, que derrubou o governo de Salvador Allende, em 1973, partiu para o seu segundo exílio: o México. Aí integrou-se à UNAM (Universidade Autônoma do México), assumindo a direção da sua Divisão de Pós-graduação e a coordenação do Doutoramento em Economia.

Theotônio foi provavelmente quem mais esforços analíticos empreendeu na projeção internacional da Teoria da Dependência, entre os seus founding fathers, concebendo-a, em suas derradeiras abordagens, como uma primeira etapa da construção de uma Teoria do Sistema Mundial, num diálogo teórico constante, por exemplo, com Immanuel Wallerstein e Giovanni Arrighi. Ou seja, ao fim, ele levou a Teoria da Dependência ao encontro com a Escola do Sistema-Mundo. Em 2013, foi galardoado com o Prêmio Mundial de Economista Marxiano da Associação Mundial de Economia Política.

O seu último livro foi Desenvolvimento e Civilização: Homenagem a Celso Furtado ${ }^{5}$, e é sobretudo ele que aqui me interessa, nomeadamente o seu primeiro capítulo, quer dizer, Teses sobre a Herança Neoliberal (isto sem desconsiderar a significativa relevância do restante do trabalho). O valor desse primeiro capítulo, contudo, assenta no facto, como assinala o próprio Theotônio, de os temas do neoliberalismo e de sua herança para as ciências sociais, para as políticas públicas e para os povos do planeta - designadamente os situados na periferia e semiperiferia

5 Ver DOS SANTOS, Theotônio, Desenvolvimento e civilização: homenagem a Celso Furtado, Rio de Janeiro: EdUERJ, 2016. 
- serem objeto de vários estudos sem que, no entanto, por vezes, se tenha uma compreensão integral a seu respeito. Por outro lado, também ocorre de abordagens não superarem o tom meramente panfletário, sem densidade analítica.

Dos Santos caracteriza o neoliberalismo como um pensamento único que representa um esforço reacionário, no sentido rigoroso deste conceito, como reação: tentativa de fazer retroceder a história a fórmulas ultrapassadas das relações econômicas. Trata-se, assim, de um pensamento que busca deter as conquistas sociais e políticas alcançadas pelos segmentos sociais emergentes no interior do capitalismo, durante os seus períodos de auge econômico, particularmente, a fase posterior à Segunda Guerra Mundial, marcada pelo Estado de Bem-estar nos países centrais, pela expansão das então economias ditas do socialismo real em torno da antiga União Soviética e pelos novos Estados emergentes da descolonização e das lutas nacionais democráticas, nas zonas periféricas em geral.

Ele faz um histórico da ascensão neoliberal enfatizando que, depois da Segunda Guerra Mundial, um pequeno grupo reunido em torno do economista Friedrich Hayek e da Escola de Economia da Universidade de Chicago marcou posição reagindo à orientação político-econômica e social em curso no mundo. Emerge assim o neoliberalismo. O referido grupo recorria à proto-história, pretendendo o regresso do individualismo utilitarista do século XVIII. Com o advento das ditaduras militares na América Latina, foi proporcionado aos porta-vozes do neoliberalismo uma espécie de laboratório para levarem a cabo as suas receitas: o Chile, sob a cruel ditadura do general Augusto Pinochet. Logo no princípio da sua adoção no Chile, o neoliberalismo elevou o desemprego a algo em torno de $30 \%{ }^{6}$, dando marcha à estruturação de uma sociedade com desigualdades extremas facto este que atualmente tem gerado turbulentos protestos-, com a revolta social sendo contida, na época, pela ferocidade da ditadura. Nos países centrais, foi na Inglaterra, sob Thatcher, e nos EUA, com Regan, que o neoliberalismo alcançou o seu ponto mais alto.

Isto posto, Theotônio dos Santos apresenta onze teses sobre o que ele denomina 'herança do neoliberalismo'. Passo a um realce analítico de cada uma delas, num movimento em que, ao mesmo tempo que as descreve, agrega considerações a seu respeito.

\section{Da análise à arma da crítica: teses sobre a herança neoliberal}

A primeira é que o neoliberalismo é uma corrente de pensamento que tem suas raízes no liberalismo do século XVIII, a cujo universo teórico continua submetido, ignorando o avanço da filosofia e das ciências humanas dos séculos posteriores. 
Seu nível teórico é, portanto, extremamente baixo, fazendo recuar o pensamento social contemporâneo a princípios teóricos e metodológicos superados.

Dessa forma, como entende Dos Santos, o neoliberalismo opera, por exemplo, com dois postulados falsos, quais sejam: i) a ideia de que o indivíduo é o fundamento da sociedade e do Estado; ii) a noção absoluta de livre mercado. Entretanto, conforme contesta ele, a ideia de que o indivíduo é o fundamento da sociedade e do Estado não tem suporte histórico algum. As comunidades primitivas não permitiam aos seus componentes se identificarem como indivíduos separados delas, como demonstram os estudos antropológicos desenvolvidos desde o século XIX. A noção de indivíduo é resultado do progresso histórico que produziu tal avanço das forças produtivas que uma parte da população (os que possuem a propriedade privada) pôde destacar-se da comunidade e forjar uma sociedade fundada no reconhecimento das individualidades. O individualismo não é a origem da História, e sim um resultado da mesma, não é o fundamento da natureza humana, mas, na verdade, o resultado de um processo social e histórico. Ele surge num momento histórico determinado, e tudo indica que deverá assumir formas novas superiores com a sua evolução histórica. O conceito de natureza humana é, portanto, uma construção metafísica com acentuadas implicações político-ideológicas ${ }^{7}$. Quando à noção de livre mercado, há que se ter em conta que ela foi uma espécie de "tipo ideal" (um "modelo") criado pela ascensão burguesa, no século XVIII, objetivando instituir um mundo à sua imagem e semelhança. Assim, a noção de livre mercado emerge como uma "ideia-força" que auxiliou no estabelecimento de uma sociedade, de uma economia e de um regime político próximo à visão da classe social então em ascensão.

A segunda tese assinala que o neoliberalismo é um movimento ideológico reacionário (próprio das fases de recessão econômica global dos ciclos de Kondratiev) que pretende deter as transformações socioeconômicas derivadas das fases de crescimento e avanços globais, identificadas por Kondratiev, próprias do funcionamento do capitalismo contemporâneo.

Esse é um movimento, claro está, que se encontra condicionado por dois vetores. Primeiro: a tendência à queda da taxa de lucros, originada pela importância crescente dos gastos em maquinários e matérias-primas (capital constante) que acompanham as inovações tecnológicas (aumento da composição orgânica do capital), e ocasionada também, por outro lado, pelo aumento da capacidade do trabalho assalariado de obter melhores condições de remuneração, como consequência do pleno emprego gerado nos períodos de auge econômico. Essa tendência impulsiona, sistematicamente, o capital a buscar as contratendências que podem conduzir a formas de "socialização da propriedade privada", que levam a

7 A propósito, convém lembrar que esse tipo de "retórica metafísica" - apelando para a "natureza humana", "intuição", "instintos" - insere-se naquilo que Lukács via como rebaixamento teórico e irracionalismo como princípio filosófico, um assalto à razão, destruindo-a. Cf. LUKÁCS, György, The destruction of reason, London: Merli, 1980. 
expandir a ação do capitalismo estatal constituindo instrumentos privilegiados para neutralizar, em parte, a queda da taxa de lucros, por meio de vários mecanismos de transferências de valor. Segundo vetor: a implantação da Revolução Científico-Técnica, nos anos 1940, estimulada pelas vantagens oferecidas pela aplicação das inovações tecnológicas na competição capitalista. Esta, entretanto, é produtora de uma lógica própria que provoca um impacto radical sobre as inovações tecnológicas e o funcionamento do capitalismo, no sentido de reduzir o tempo de trabalho socialmente necessário para a produção das mercadorias, diminuindo as possibilidades de funcionamento da lei do valor e das relações mercantis puras em decorrência da ação do "capitalismo estatal".

$\mathrm{Na}$ terceira tese, Theotônio dos Santos afirma que, para ter alguma significação no mundo real, a "ciência" econômica [as aspas em ciência são dele] ensaia um conjunto de propostas empíricas sem se ater aos seus princípios teóricos, alcançando alguns resultados empíricos. Trata-se de um mundo do empirismo e do pragmatismo total, que dificilmente permite acumular conhecimento.

Depreende-se que, dessa prática, são gerados efeitos danosos, por exemplo, à formulação de políticas públicas, em particular, no que diz respeito à política macroecnômica. Isto porque, neste caso, lança-se mão de um pragmatismo exacerbado a serviço de interesses tacanhos. Realiza-se uma operação "científica" que reduz o campo da política econômica ao curto prazo, tendo em vista medidas que objetivam o dito "pleno funcionamento do livre mercado", ocultando elementos de caráter ideológico por via de formulações metafísicas.

Quanto à quarta tese, Dos Santos a elabora de modo estendido para articular livre-câmbio, comércio mundial e a divisão internacional do trabalho, apresentando-a do seguinte modo: o livre-câmbio era um projeto das burguesias industriais nos países já industrializados, mas, ao mesmo tempo, era um projeto das burguesias agrárias e mineiras exportadoras, dos países dependentes e periféricos, mesmo nas zonas em emergência no século XX. Na fase atual do capitalismo mundial, criou-se um setor intermediário do capital financeiro internacional que recebe a maior parte do excedente nacional sob a forma de altos juros e outros mecanismos de expropriação dos valores produzidos por toda a população. O comércio mundial não é uma totalidade horizontal e sim o resultado de uma divisão internacional do trabalho. Ele está submetido também ao movimento internacional de capitais, sejam produtivos, sejam especulativos. O comércio mundial e o intercâmbio de serviços e de capitais formam um sistema global no qual algumas nações controlavam - e ainda controlam - as tecnologias centrais de cada sistema produtivo, de distribuição de produtos e valores. Ao mesmo tempo, outras nações se especializam em tecnologias e relações socioeconômicas que ocupam um papel subordinado e local no sistema científico e tecnológico planetário.

A divisão internacional do trabalho é, assim, um sistema desigual e combinado, que reforça e recria, no seu entorno, um mundo desigual e combinado. Este 
é implantado pela força econômica e militar, a partir dos países centrais colonizadores imperialistas, com o apoio e a cumplicidade das classes "dominantes-dominadas" que se articulam com esse sistema global por meio de sua especialização subordinada.

Trata-se de uma tese fortemente sintonizada com as abordagens da Teoria da Dependência. Conforme esta demonstrou, a articulação entre as classes dominantes do centro e da periferia encontra fortes bases sociais e institucionais internas. O excesso artificial de mão de obra, criado pela propriedade latifundiária, exclui da posse da terra as massas escravizadas africanas e indígenas, com uma incorporação mais favorável, mas ainda negativa, dos imigrantes europeus e asiáticos da segunda metade do século XIX e da primeira metade do século XX. Foi nesse ambiente que Ruy Mauro Marini, em sua Dialética da Dependência, apontou a superexploração do trabalho ${ }^{8}$. Assim como Andre Gunder Frank expôs como o livre-câmbio se constituiu num mecanismo privilegiado para favorecer a expropriação mundial de excedentes, onde o excedente gerado na periferia é favorável ao centro do sistema, fazendo surgir uma movimentação econômica em que a extração do excedente é fundamento mesmo do sistema capitalista mundial ${ }^{9}$.

A quinta tese é formulada nos seguintes termos: A partir das premissas falsas que ignoram a evolução necessária do capitalismo no sentido de uma economia monopólica e estatizante, o neoliberalismo não pode colocar em prática suas deduções de políticas econômicas. Na realidade, ele é usado como instrumento ideológico para justificar objetivos táticos, mas, no seu conjunto, não modifica a tendência monopolista e estatizante do "capitalismo maduro". A partir de uma definição metafísica da natureza humana (o indivíduo possessivo) e de uma construção teórica, também metafísica, do chamado "livre mercado", as ciências sociais burguesas e, especialmente, a economia, deduzem delas um comportamento econômico determinado. Este é ajustado aos instrumentos teóricos desenvolvidos pela atividade científica do final do século XVIII e, posteriormente, aos instrumentos científicos desenvolvidos no século XIX até o começo do século XX.

O que está em causa, nesta tese, é, entre outras coisas, o realce na tentativa de transferir para as ciências humanas o êxito da física em deduzir, das noções ideais de um universo composto do espaço geométrico e do tempo histórico sem direção - como lei do movimento -, uma dinâmica e uma mecânica que se mostraram extremamente úteis para submeter a natureza aos objetivos humanos. Contudo, é ignorado que o triunfo da mecânica excluía o tempo histórico ${ }^{10}$ e os fenómenos da vida em geral e da vida humana em particular. A propósito, é revelador que Darwin, ao tentar aplicar as técnicas científicas de observação e dedução que

8 Ver MARINI, Ruy Mauro, Dialética da dependência, Petrópolis, RJ: Vozes, 2000.

9 Cf. FRANK, Andre Gunder, Capitalism and Underdevelopment in Latin America, Nova York: Monthly Review Press, 1967.

10 A "flecha do tempo", como diz Prigogine. A esse respeito, ver PRIGOGINE, llya \& STENGERS, Isabelle, Entre o tempo e a eternidade, São Paulo: Companhia das Letras, 1992. 
se desenvolveram no século XIX aos fenômenos vitais, tenha se visto obrigado a incluir a história natural em seus estudos empíricos e a produzir uma teoria da evolução biológica, inclusive dos seres humanos. A ciência introduzia, assim, novos elementos históricos, que sensibilizaram algumas correntes das ciências humanas.

Contemporaneamente, é cada vez mais despropositado querer voltar às dimensões estáticas que deram corpo, por exemplo, a elaborações de Karl Popper. Já em 1940, Adorno, em seu debate com ele, demonstrou o limite do enfoque popperiano, isto é, a redução do racional ao instrumentalismo ${ }^{11}$. Portanto, importa enfatizar o atraso teórico da démarche neoliberal, ao que se soma o seu atraso no que se refere à concepção moderna de sociedade e economia capitalistas. Pretende regressar a um mundo do livre mercado que nunca existiu totalmente, em plena época do capitalismo monopólico, desconhecendo a evolução da tecnologia, da ciência e do conhecimento.

Na sexta tese, Theotônio dos Santos infere consequências da limitação teórica neoliberal. Segundo ele, a deficiência teórica do neoliberalismo não lhe permite propor políticas econômicas viáveis. Na prática, ressalta ele, os seus representantes terminam colocando-se a serviço de propostas de política ad hoc, a serviço de interesses específicos, o que não lhes permite ter qualquer ideia da consequência delas: é assim que os teóricos do equilíbrio parcial ou geral - conforme as suas inúteis discussões - terminam favorecendo os maiores desequilíbrios da história econômica mundial.

De facto, esta tese pode ser validada empiricamente quando são considerados os resultados da política econômica imposta pelo governo neoliberal de Ronald Regan nos Estados Unidos, entre 1983 e 1987. Ela levou a uma certa recuperação econômica nesses cinco anos. Porém, os princípios doutrinários que conduziram a recuperação não encontram fundamento algum nos princípios neoliberais. Tratou-se, isto sim, de um "ousado" e aventureiro mergulho da economia mundial num desequilíbrio colossal. Indo em direção oposta às diretrizes neoliberais, que exigiam o equilíbrio fiscal, cambial e monetário como condição macroeconômica para o pleno funcionamento da economia de mercado, a origem do auge econômico de 1983 a 1987 encontra-se no mecanismo do déficit do Tesouro estadunidense, que alcançou a cifra de 134 bilhões de dólares em 1982, de 230,8 bilhões em 1983, mantendo-se nesse patamar até 1989, com 237,8 bilhões ${ }^{12}$. O déficit fiscal havia se situado, na década de 1970, em torno dos 50 bilhões de dólares anuais, o que levou a um amplo movimento pela contenção dos gastos ou pelo aumento dos impostos no país. O governo Reagan descartou a segunda hipótese (chegando,

11 O debate entre Adorno e Popper ficou conhecido como "o confronto positivismo e dialética". A propósito, ver GANEM, Angela, "Karl Popper versus Adorno: lições de um confronto histórico", in Revista de Economia Política, vol. 32, n 1, pp. 87-108, disponível em: <http://www.scielo.br/scielo.php?script=sci_arttext\&pi $\mathrm{d}=$ S0101-31572012000100006>. Acessado em: 10 /02/2020.

12 Também cf. Theotônio dos Santos, no livro Do terror à esperança: auge e declínio do neoli-beralismo (Aparecida, SP: Ideias \& Letras, 2004) 
inclusive, a reduzir os impostos sobre o capital e as altas rendas) e realizou cortes de despesas somente nos gastos sociais.

Na sétima tese é afirmado que, a partir de 1994, se inicia uma nova fase de crescimento da economia mundial. Entretanto, nos primeiros anos, entre 1994 e 2001, apresentaram-se - sobretudo nas zonas periféricas e semiperiféricas - crises, particularmente no setor financeiro e cambial, que representavam mecanismos de ajuste do sistema econômico mundial a essa nova fase de crescimento econômico global, a qual se inscreve nos ciclos longos de Kondratiev.

Cabe sublinhar que, segundo esses ciclos, descobertos pelo economista russo que lhe atribui a denominação, a economia mundial se move em períodos de cinquenta a sessenta anos. Estes são caracterizados por uma primeira fase (A), na qual predominam os anos de crescimento econômico e se moderam as recessões, durando por volta de vinte e cinco/trinta anos, seguindo-se as etapas B do ciclo longo, que se caracterizam por períodos equivalentes, dominados, predominantemente, por recessões, com moderadas retomadas de crescimento. Posto isto, o mencionado crescimento (fase iniciada em 1994) rompeu na prática, conforme Dos Santos, com o quadro ideológico instituído pelo neoliberalismo durante a fase B do ciclo, que vai de 1940-45 a 1994-98.

Nessa fase, iniciada em 1967-73, a economia mundial caracterizou-se pela recessão, com alguns períodos de recuperação. Todavia, essa recuperação esteve apoiada em factores artificiais, mantidos por um intervencionismo estatal de novo tipo, totalmente favorável ao capital financeiro. Esse novo intervencionismo caracteriza-se por enormes desequilíbrios fiscais e cambiais que provocam uma forte pressão sobre a variação das moedas e sobre o capital financeiro (particularmente, a taxa de juros).

Nesse contexto, a chamada crise asiática, iniciada em 1997, permitiu ao Japão e aos Tigres Asiáticos o reajuste de seus tipos de câmbio, o que deu início a um novo período de crescimento, que já se esboçava em 1999, mas que foi frustrado pela política recessiva do Fed, em 2001. A Rússia, que foi envolvida nessa crise por distintas razões, apelou para a moratória e colocou-se no caminho de uma redefinição política que viabilizou sua recuperação econômica a partir de 1999. Neste cenário, a situação brasileira é bastante singular, até mesmo considerando quem estava no exercício da Presidência do país, alguém que, nos anos 1960, foi um dos formuladores da Teoria da Dependência, numa versão própria e que posteriormente seguiu outras perspectivas. O Brasil fez um ajuste cambial atrasado e que só foi possível devido ao apoio do sistema financeiro internacional à reeleição de Fernando Henrique Cardoso. O país passou por uma grave crise em 1998, em consequência de irresponsabilidades na gestão da política econômica, sendo esta redefinida, em parte, com a desvalorização cambial realizada em janeiro de 1999. Apesar disto, continuou com a imprópria adoção de juros altos, o que comprometeu radicalmente a estabilidade fiscal e inviabilizou a retomada do crescimento 
econômico e o saneamento da economia. Essa situação levou o partido de Fernando Henrique Cardoso à derrota eleitoral, na sua sucessão, com ele deixando o país com uma inflação de 13\%, uma dívida internacional sem cobertura (com os seus pagamentos adiados pelo FMI), uma dívida interna vinte vezes superior à dívida da qual partiu o seu plano econômico (o Plano Real) e taxas de crescimento econômico de cerca de $2 \%$, em média, num país onde a população crescia a cerca de $1,8 \%$ (o que representa uma quase estagnação da renda per capita por oito anos, período este de duração dos governos de Cardoso) ${ }^{13}$. A oitava tese evidencia o papel do FMI, do Banco Mundial e os efeitos das suas propostas. Conforme Theotônio dos Santos, a intervenção doutrinária e política do Fundo Monetário Internacional e do Banco Mundial tem um sentido profundamente conservador. Ela é uma das heranças mais negativas do período hegemônico do neoliberalismo. Na década de 1990, a baixa das taxas de juros permitiu a recuperação econômica dos Estados Unidos e da Europa e a queda de seus déficits fiscais. A principal origem do déficit fiscal não se encontrava nos gastos públicos, mas nos altos juros. Porém, nos ditos países emergentes, primeiro sob o domínio das políticas de ajuste estrutural (década de 1980) e, depois, com o chamado Consenso de Washington, as taxas de juros subiram às máximas alturas e atraíram os capitais voláteis, que abandonavam os mercados dos países centrais, pois estes se encontravam em queda. Essa queda manifestava-se pela desvalorização de ativos monetários, financeiros e imóveis, ao mesmo tempo em que se baixavam as taxas de juros e se controlavam os déficits públicos.

Daí claramente se pode inferir, por exemplo, que a intervenção do FMI se converteu numa fonte de problemas, e não num factor de solução de crises. Suas recomendações, na periferia e semiperiferia do sistema, acentuaram os desequilíbrios fundamentais das economias, inviabilizando sua capacidade de recuperação e as levando à recessão e ao desastre político e econômico.

A nona tese aponta as incongruências da socialdemocracia tradicional perante o neoliberalismo. Realça que os governos que ela gerou ficaram limitados em suas políticas econômicas, tentando conciliar uma política neoliberal na economia (considerada a única científica, isto é, a aceitação do pensamento único) e uma política social pretensamente tributária do socialismo socialdemocrata. Como a política social e todas as políticas públicas dependem da sua base macroeconômica, elas se mostraram muito pouco profundas. Disso pode ser dito que resulta um desafio fundamental: ou se rompe com a base doutrinária do pensamento econômico único e se estabelece uma nova agenda de políticas públicas ou se afundam os governos, quaisquer que sejam seus signos políticos.

Na décima tese, Dos Santos articula macro e microeconomia. É incisivo ao argumentar que somente a baixa das taxas de juros e o "desvio" ao vasto movimento especulativo e dos sistemas financeiros artificiais que ela gerou puseram, 
um pouco, a economia mundial a delinear um novo caminho. Destaca que a crise financeira asiática foi um dos últimos momentos deste quadro de crise mais geral, havendo um certo desafogo no sistema financeiro mundial nos anos seguintes, apesar de os Estados nacionais terem continuado a proteger um vasto setor financeiro claramente especulativo e inútil. A situação mais negativa, aponta, persistiu nos países de desenvolvimento médio, como os latino-americanos, onde se mantiveram as políticas de altas taxas de juros e de proteção estatal ao capital especulativo, que perdia espaço no resto do mundo. Essa situação foi revertida (em parte) a partir de 2002, com a forte aparição, na economia mundial, da demanda chinesa, sobretudo de matérias-primas e de produtos agrícolas. Isto permitiu que quase todos os países da região aumentassem várias vezes as suas exportações, criando um persistente superávit comercial e, consequentemente, de suas reservas. O que tornou possível que, durante a crise de 2008 , esses países sofressem suas consequências de maneira muito marginal, já que a demanda chinesa continuou, em função da manutenção do crescimento econômico daquele país e, também, das áreas vizinhas, particularmente Índia, Rússia, Indonésia e até o Japão, cada vez mais caudatários da lógica de acumulação que se expandiu a partir da região do Sudeste Asiático. A crise do sector financeiro adquiriu dimensões gigantescas, manifestadas na tendência recessiva dos anos 2008 e 2009, cuja resposta, sob a forma da ampliação excessiva do déficit público para sustentar um setor financeiro inútil, prolonga a crise, sob a forma de baixo crescimento do PIB e de violento crescimento do déficit público e das dívidas soberanas dos países centrais.

Isto, de outra parte, como reconhece Dos Santos, não mudou as condições negativas para os países em desenvolvimento, pois os fez substituir o desenvolvimento verdadeiro, voltado para a atenção às necessidades de sua população, pela opção de jogar a carta do crescimento das exportações de matérias-primas e de produtos agrícolas. A preferência por manter enormes reservas, ao invés de investir em infraestrutura e em desenvolvimento social, educação, saúde e, particularmente, no desenvolvimento científico-tecnológico, ameaça punir esses países por não aproveitarem as oportunidades criadas pelas circunstâncias econômicas. Dessa forma, então, a questão política converte-se em ponto central para a previsão e a compreensão das forças que influem nos seus destinos. É isto que, sem dúvida, está posto aos cidadãos e cidadãs das diversas nações, e não só periféricas e semiperiféricas.

A décima primeira, e última, tese tem a ver com o alcance da herança neoliberal. Theotônio dos Santos é paradigmático a este respeito: A penetração da herança neoliberal na academia e nos meios de comunicação reforçou-se com a sua introdução nos partidos políticos de centro-esquerda. Criou-se um ambiente de terrorismo ideológico que paralisou muitos esforços teóricos. Aceitam-se as afirmações dogmáticas do neoliberalismo contra o planejamento. Estas "verdades", segundo se acredita, teriam se confirmado com o fracasso ou a derrota das 
experiências socialistas na Europa Oriental e na ex-URSS. Claramente, não se tem em conta o facto de que o princípio do planejamento orienta a ação das empresas transnacionais ou globais e as políticas industriais do Estado moderno. Os dados mostram que os gastos públicos são cada vez mais importantes nos países capitalistas centrais. Apesar do neoliberalismo, cada vez se faz mais clara a impossibilidade de se organizar a economia mundial sem políticas de longo prazo e sem planejamento econômico, político, social e cultural.

Os factos, contudo, são "teimosos", e como a História é movimento, é de se ter a expectativa - apoiada na ação das forças que laboram na sociedade em torno de novos projetos - que o referido alcance hegemônico da herança neoliberal seja superado.

\section{À guisa da conclusão}

Ao fim e ao cabo, as onze teses de Theotônio dos Santos sobre a herança do neoliberalismo abrem caminho e apontam para uma agenda pós-neoliberal, onde constem como pontos centrais a preeminência do político sobre o econômico (do planejamento sobre o mercado), do emprego e do crescimento econômico sobre o puro equilíbrio fiscal e macroeconômico, do avanço científico e tecnológico a serviço da humanidade, do desenvolvimento humano sobre os critérios economicistas de crescimento, etc.

Trata-se, por certo, de uma perspectiva que caminha em sentido distinto das ideias que, inebriadas de ideologia, proclamam o fim da História sob a ortodoxia de uma sociedade lastreada pelo neoliberalismo. Na realidade, a História não tem fim. Talvez, de um certo ponto de vista, ela recém começa em nosso tempo, quando a subjetividade humana inicia a sua marcha objetivando se afirmar integralmente, em escala global, e buscando construir uma cidadania planetária equânime e com equidade. O avanço dessa construção dependerá, em certa medida, da capacidade de se usar a razão na interpretação do que é germinado pelas "sementes do tempo". Cabe decifrar, portanto, aquelas flores que Walter Benjamin refere em sua tese IV sobre o Conceito de História: como corolas que, por um secreto heliotropismo, voltam-se para o sol que está a se levantar no céu da História. 